\title{
REVIEW OF RESEARCH RESULTS CONCERNING THE MODELLING OF SHIPPING NOISE
}

\author{
Xiaowei $\operatorname{Yan}^{\star 1)}$ \\ Hao Song ${ }^{1)}$ \\ Zilong Peng ${ }^{2)}$ \\ Huimin Kong ${ }^{2)}$ \\ Yipeng Cheng ${ }^{2}$ \\ Linjiang Han $^{2)}$ \\ 1) Systems Engineering Research Institute, China \\ 2) Jiangsu University of Science and Technology, China \\ * Corresponding author: yanxwseri@163.com (X. Yan)
}

\begin{abstract}
The effect of underwater radiated noise (URN) pollution (produced by merchant ships) on marine ecology has become a topic of extreme concern for both the academic community and the general public. This paper summarises some research results and modelling about shipping noise published over several decades, which comprises the research significance of low-frequency ambient noise and shipping noise, shipping noise source levels (SL), empirical models and the measurement standards of shipping noise. In short, we try to present an overall outline of shipping noise and ocean ambient noise for related research.
\end{abstract}

Keywords: shipping noise,noise source level model,measurement standard,ocean ambient noise

\section{INTRODUCTION}

The National Research Council [1] states that it is an important research task to evaluate the effect of man-made noise and natural noise on overall ambient marine noise and to study the long-term trend of ambient noise levels. The prosperity brought by industrialisation and the shipping industry since the middle of the $19^{\text {th }}$ century has lead to increasing levels of ambient noise, which was predicted to continue to increase in recent years, but there is a lack of sufficient evidence. Studies have shown that noise from different ship classes greatly increase the level of ambient marine noise, at frequencies of $25 \mathrm{~Hz} \sim 16 \mathrm{kHz}$ with a horizontal distance of $60 \mathrm{~m} \sim 1 \mathrm{~km} \mathrm{[2].} \mathrm{Ross} \mathrm{[3]} \mathrm{analysed} \mathrm{noise} \mathrm{levels}$ measured in the mid- $20^{\text {th }}$ century and pointed out that the low-frequency noise was increasing at an average growth rate of $0.5 \mathrm{~dB}$ /year. It was later proved, by the measured data, that this growth rate was actually closer to $0.2 \mathrm{~dB} /$ year [4]. Some recent measurements by Andrew et al. in the northeast Pacific Ocean indicate a slight decrease [5].

In recent years, with the extensive usage of vibration and noise control technology in submarines, both their radiated noise and the target strength (TS) were significantly reduced, which greatly increases detection difficulty for active or passive sonars. Although some acoustic stealth techniques can reduce the target strength and radiated noise level (RNL) at mediumhigh frequencies, it seems to have no significant effect at low frequencies, below several hundred Hertz [6]. Some of the 
measured data indicates that $90 \%$ of the noise below $300 \mathrm{~Hz}$ radiated from submarines or merchant ships is abundant, with strong tones and instantaneous signal components, which are of great significance for the identification and tracking of submarines or merchant ships. Therefore, low-frequency acoustic detection will be an important trend, especially for long-range detection, and some new challenges will also be brought. One of the bottlenecks is the basic research on the low-frequency ocean ambient noise field, at present there is still a lack of more scientific theories and effective methods.

As indicated in Wenz' classical deep-sea ambient noise spectrum [7], the low-frequency ambient noise is generated by widely distributed, multiple and complex sources including wind noise, merchant ships, crustal movements, ocean turbulence and human industrial activities, etc. These noise sources are the main disturbance for the active and passive sonars. Meanwhile, they also provide important shelter for submarine and unmanned underwater vehicles (UUV), to achieve stealth activities. The low-frequency acoustic waves, no higher than several hundred Hertz but higher than the cut-off frequency for certain depths of ocean channel, can travel long distances with relatively little attenuation [8]. Thus, for a certain receiving point in the ocean, there are abundant contributory sources from low-frequency ambient noise fields with a large distribution range [9]. Due to the diversity and distribution of the noise sources in different sea areas, the spectral components of low-frequency, ambient noise are more complex than those at medium-high frequencies.

The shipping noise and the wind noise are dominant at low frequencies, and their proportion mainly depends on the busyness of routes as well as wind intensity. The shipping noise presents great variability in both space and time, of which the spatial variability mainly depends on the distribution of routes and the time variability mainly depends on the time arrangement of shipping operations. Shipping noise has a great influence on the spatial distribution of low-frequency ambient noise, for example, the vertical directivity of the noise field shows 'groove' characteristics in the deep sea [10-11].

In the present paper, we intend to provide an appraisal of some measurements and modelling of shipping noise. It is considered by the authors that such a review will be of value to developing the subject of shipping noise as an introduction to the field, consolidating the literature on this topic which is spread among ambient ocean noise and underwater acoustic journals. The paper is structured as follows: (2) a description of the research significance of shipping noise, (3) an overall review of the research work on shipping noise, (4) a summary and analysis of empirical source level models, collected from some published papers and reports and compared, and (5) a collection of standards and methods for the measurement of shipping noise.

\section{THE RESEARCH SIGNIFICANCE OF SHIPPING NOISE}

In the published academic papers and scientific reports, there are nearly ten models for modelling the shipping noise, and at least seven models nominally can predict shipping noise under $100 \mathrm{~Hz}$, but needs more measured data to verify their accuracy. Some comparison results of some measured data and predictions using the above models are presented, and the SL obtained from underwater noise radiated from four cargo ships observed in the area of the East China Sea $[12,13]$. Table 1 summarises the design and operational conditions for the transiting ships. The SLs of transiting ships listed in Tab.1 are predicted using several empirical models (Urick model [14], Ross model [15], W\&H model [16] and RANDI-3 model [17]), and the measured SLs are the combination of received level (RL) and transmission loss (TL) estimated using Normal Modes or Ray Method combining with the realistic geoacoustic parameters and sound speed profile (SSP), that is $\mathrm{SL}=\mathrm{RL}+\mathrm{TL}$, and the estimations and measurements of these four merchant ships are presented in Fig. 1.

Tab. 1. Summary of commercial ship characteristics

\begin{tabular}{|l|c|c|c|c|c|}
\hline Ship type & MMSI & $\begin{array}{c}\text { Length/ } \\
\text { Draught } \\
(\mathbf{m})\end{array}$ & $\begin{array}{c}\text { Speed } \\
(\mathbf{k t})\end{array}$ & $\begin{array}{c}\text { Range } \\
\text { at CPA } \\
\mathbf{( m )}\end{array}$ & $\begin{array}{c}\text { Measured } \\
\text { date }\end{array}$ \\
\hline $\begin{array}{l}\text { Bulk } \\
\text { carrier }\end{array}$ & 412378670 & $173.0 / 7.0$ & 9.1 & 806.7 & Jan., 2015 \\
\hline $\begin{array}{l}\text { Container } \\
\text { ship }\end{array}$ & 372748000 & $140.0 / 8.0$ & 13.8 & 617.7 & Feb., 2015 \\
\hline $\begin{array}{l}\text { Bulk } \\
\text { carrier }\end{array}$ & 413794000 & $140.0 / 4.5$ & 9.1 & 855.3 & Mar., 2015 \\
\hline $\begin{array}{l}\text { Container } \\
\text { ship }\end{array}$ & 412499000 & $136.0 / 7.6$ & 7.5 & 1122.6 & Apr., 2015 \\
\hline
\end{tabular}

As illustrated in Fig. 1, even for the same ship, the predictions with Ross model, W\&H model and Urick model are different (the maximum difference is $\sim 20 \mathrm{~dB}$ ), not to mention how consistent are these predictions with the measured results. Measured SLs above $100 \mathrm{~Hz}$ decreased approximately with $-\mathrm{N} \lg f$, and $\mathrm{N}$ is about 16.6 32.5. But for the frequencies below $100 \mathrm{~Hz}$, the frequency dependency of source level is not monotonous and relatively complicated. In general, there is a significant hump whose shape, position and level will be influenced by the shipping speed as shown in measured results by U.S. Surface Warfare Center in Fig. 2 [18]. Although the trends of the measured results above $100 \mathrm{~Hz}$ are basically consistent with those of the empirical models, there is still a great gap in levels. 

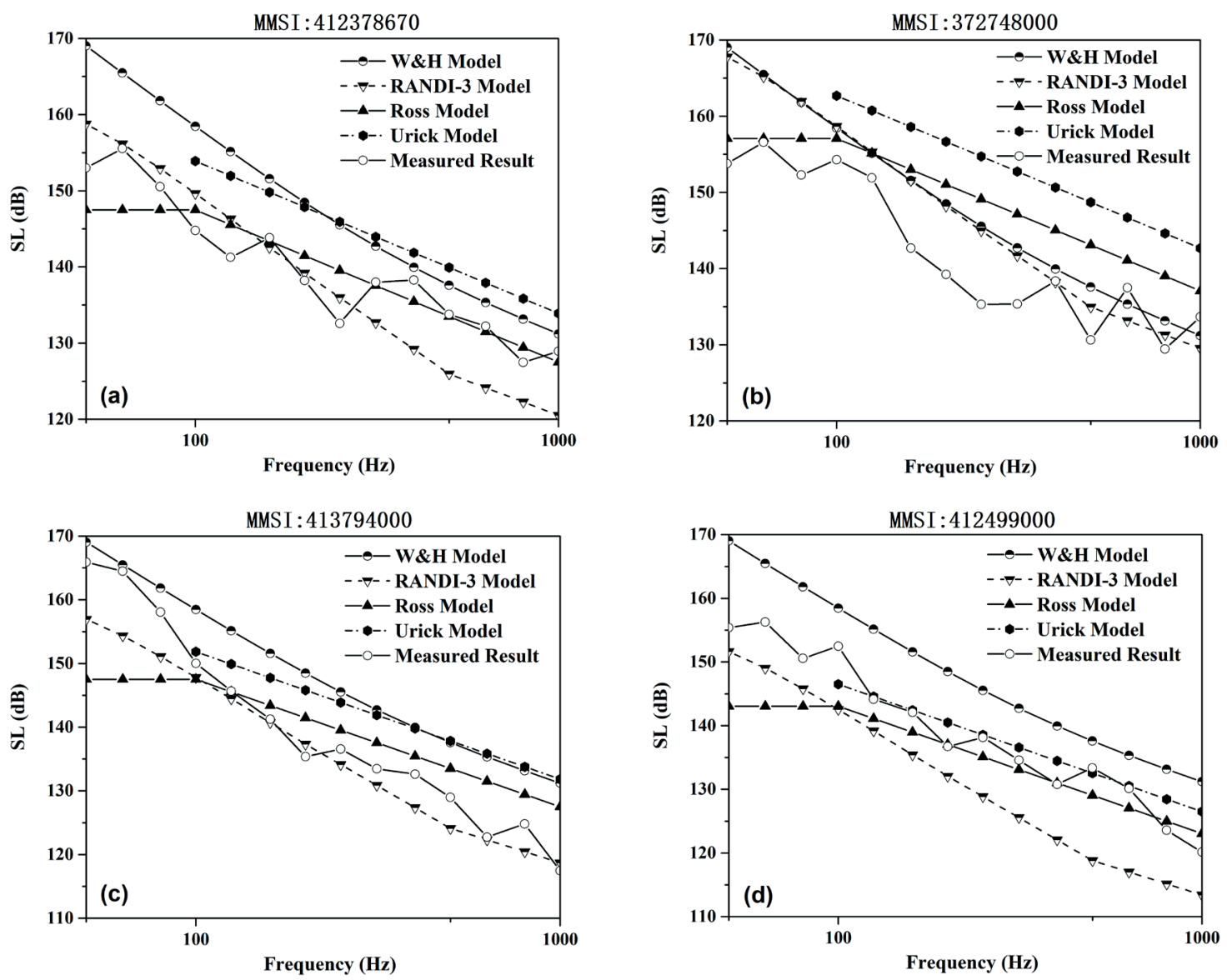

Fig. 1. Comparisons between estimations and measurements of selected ships [11,12]

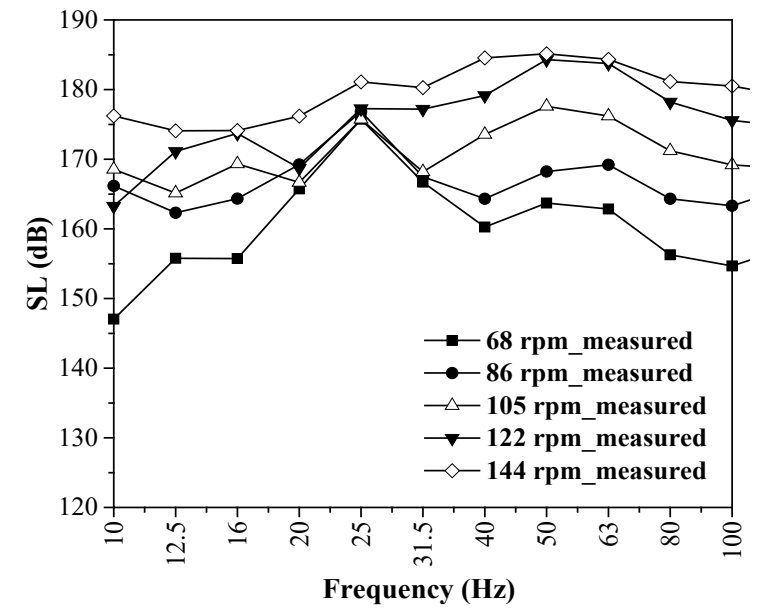

Fig. 2. Source level of cargo ship "Ov. Harriette" measured by U.S. Navy [17]

Furthermore, the median SLs of different ship types are also different greatly. Scott Veirs et al. [19] estimated underwater sound pressure levels for 1,582 unique ships that transited the core critical habitat of the endangered Southern Resident killer whales during 28 months in Haro Strait (WA, USA), and presented the median source spectra of ship noise for different classes of ships as illustrated in Fig. 3.

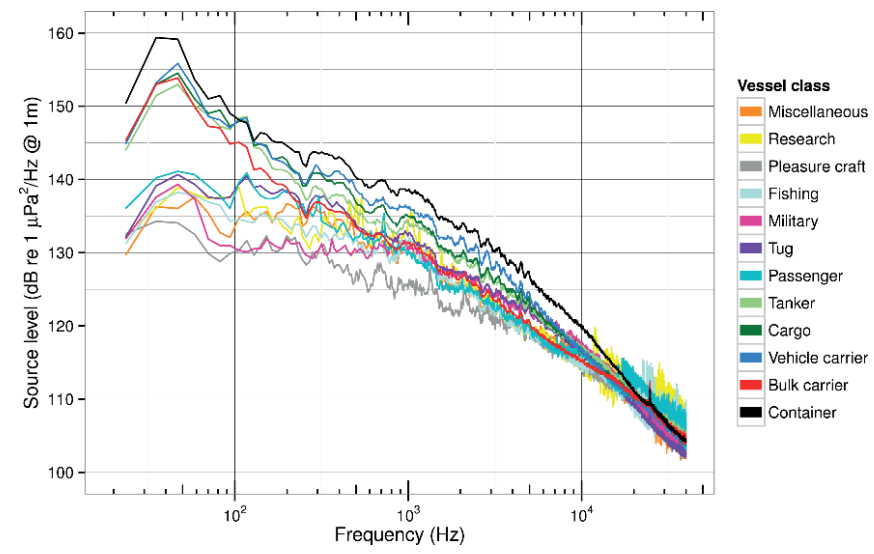

Fig. 3. Median source spectra of ship noise for different classes of ships [18]

\section{AN OVERALL REVIEW ON THE RESEARCH WORKS OF SHIPPING NOISE}

The research on the spectrum level of ambient noise was started during the World War II. A vast amount of measured data and theoretical results were classified. The wartime research was summarised by Knudsen [20]. After the war, a graphical or schematic deep-sea noise spectrum 
was published by Wenz [7], and some efforts on the shallowsea noise spectrum were made by Piggot [21]. Ross [15] and Urick [14] analysed the measured noise data of merchant ships and warships during World War II, respectively, and finally some empirical SL models of merchant ships and warships were summarised dependent on the shipping speed and ship length.

There are almost nine kinds of ship source level models published so far [14-17,22-27], which can be roughly categorised into two groups, according to modelling mechanism. One model tries to establish the fitting relationship between SL and ship speed, ship length (or tonnage) and frequency from the statistical law of amount of measured data, and the others emphasise the noise-generated mechanism, namely the superposition of mechanical noise, propeller cavitation noise and non-cavitation noise, as illustrated in Table 2. monopole source level and dipole source level (equivalent source level). The dipole source level is the most commonly used type, the significant differences between them being whether the Lloyd mirror effect of the sea surface is taken into consideration, which must be given enough attention when comparing the SLs of different ships in different publications [35].

As early as the low-frequency acoustic propagation international conference held in 1970s, the U.S. Navy initiated a new project to measure the narrowband noise of merchant ships, which aimed to develop a parametric noise model of surface ships. Supported by the U.S. Navy, the noise of the transportation ship, Ov. Harriette, was measured in 1980 [18] and this was recognised as being a considerably accurate measurement. The measurement system was deployed in the TOTO area of the Bahamas with a depth of 1,830 m.

Tab. 2. Comparison of URN models of merchant ship

\begin{tabular}{|c|c|c|c|c|c|c|c|c|c|}
\hline Model & Urick & Ross & W\&H & $\begin{array}{l}\text { RANDI-2 } \\
\text { RANDI-3 }\end{array}$ & ANATRA & Wittekind & AQUO project & Three parameters & Lurton \\
\hline Speed/length & $\sqrt{ }$ & $\sqrt{ }$ & $x$ & $\begin{array}{l}\text { Depending on } \\
\text { the type of ship }\end{array}$ & $x$ & $\sqrt{ }$ & $\sqrt{ }$ & $x$ & $x$ \\
\hline Ship types & Passenger ships & Merchant ships & Merchant ships & $\begin{array}{c}\text { Super Cruises, } \\
\text { Large Cruises, } \\
\text { Cruises, } \\
\text { Merchant Ships, } \\
\text { Fishing Vessels }\end{array}$ & $\begin{array}{l}\text { Noise (quiet, } \\
\text { Standard } \\
\text { noisy) }\end{array}$ & Merchant ships & Merchant ships & $\begin{array}{c}\text { Merchant ships } \\
\text { (Adjustable pitch } \\
\text { propeller) }\end{array}$ & Merchant ships \\
\hline Fitness $<100(\mathrm{~Hz})$ & $\times$ & $x$ & $\checkmark$ & $\sqrt{ }$ & $\sqrt{ }$ & $\sqrt{ }$ & $\sqrt{ }$ & $\sqrt{ }$ & $\sqrt{ }$ \\
\hline $\begin{array}{l}\text { Modelling } \\
\text { Mechanism }\end{array}$ & $\begin{array}{c}\text { Statistics } \\
\text { Regulation }\end{array}$ & $\begin{array}{c}\text { Statistics } \\
\text { Regulation }\end{array}$ & $\begin{array}{l}\text { Statistics } \\
\text { Regulation }\end{array}$ & $\begin{array}{l}\text { Statistics } \\
\text { Regulation }\end{array}$ & $\begin{array}{l}\text { Statistics } \\
\text { Regulation }\end{array}$ & $\begin{array}{c}\text { Noise } \\
\text { Mechanism }\end{array}$ & $\begin{array}{c}\text { Noise } \\
\text { Mechanism }\end{array}$ & $\begin{array}{l}\text { Statistics } \\
\text { Regulation }\end{array}$ & $\begin{array}{l}\text { Statistics } \\
\text { Regulation }\end{array}$ \\
\hline
\end{tabular}

Although there are already many models of shipping noise, some problems still exist. At first, almost all the models cannot predict low-frequency shipping noise below $100 \mathrm{~Hz}$ very well. Secondly, as pointed out by Yvan Simard [28], these models were established on insufficient measured data over ten years and cannot predict data for newly-built larger merchant ships worldwide. Gaggero [29] also compared the predictions using these models and the measured results. Thirdly, although both the AQUO project's model and the Wittekind's model are based on the noise mechanism $[23,30]$, the related parameters and modelling conditions are not easy to obtain. For the AQUO project's model, three main noise sources are assumed as functions of frequency and speed (at least two different speeds are required), which are difficult to obtain during the measurement of non-cooperative ships [24]. The required parameters in the Wittekind's model are much more detailed, whether the main engine is equipped with a vibration isolator is even considered.

The SL models and noise regularity must rely on a large amount of accurately measured data. Some organisations, such as ASA (Acoustical Society of America), DNV (Det Norske Veritas), ICES (International Council for the Exploration of the Sea) and ISO (International Organization for Standardization), have made a series of measurement standards or restriction standards for the URN of merchant ships [31-34]. In addition, some experts [35-37] pointed out that all the SLs of merchant ships can be categorised into
The noise data showed that high levels are attributed to service diesel generators, marine engines and cavitation blades of the propeller; the low-frequency noise radiation usually appears as a dipole pattern.

Since the 1990s, research on shipping noise has already become one of the major subjects in the international acoustic community. One of the probable reasons is that the impact of man-made noise on the marine environment has attracted more attention from supervision departments, which can be well accounted for by the content of shipping strategy framework guidance [38]. In almost all the busy shipping channels and areas worldwide, noise measurements have been made: the Mediterranean [16, 39], the North Atlantic near Europe [39], the southern Baltic [40], the ocean around the United States [41], Canada [42] and the northern Indian ocean [43]. In recent years, there has been some published research on shipping noise in the Arctic Ocean [44].

Scrimger et al. [39] measured the radiated noise of 50 merchant ships passing through the sea near Genoa. The measured median spectrum level and its shape in the range of $70 \sim 700 \mathrm{~Hz}$ were roughly consistent with the classical Ross model. In the Mediterranean Sea and the East Atlantic Ocean, Wales et al. [16] measured the noise at 30 1200 Hz, radiated from 272 merchant ships and obtained the median spectral level. Mckenna and Ross [41] measured the radiated noise of 593 container ships near the Santa Barbara Channel and studied the impact on the radiated noise of ship shape 
lines, operational configurations and sea states. Among these measured ships, bulk carriers have higher SLs near $100 \mathrm{~Hz}$, while the highest levels of container ships and tankers present at frequencies below $40 \mathrm{~Hz}$, which accounts for the influence of different ship classes on the SLs. By taking measurements on the 1,363 voyages of ships with AIS passing through Puget Sound, Bassett et al. [45] indicated that cargo ships contribute the most to the noise field, followed by tugboats and passenger ships. Coward et al. [42] made a measurement of a small cargo ship in the shallow waters of the Oslo Fjord and modified its SL to monopole form with the RAM transmission model. Roth [44] measured the underwater radiation noise of an icebreaker in the Arctic Ocean, which showed that the radiation noise of $20 \mathrm{~Hz} 2 \mathrm{kHz}$ increased by nearly $10 \mathrm{~dB}$ during icebreaking work. Trevorrow et al. [46] measured the radiated noise of a small, single-screw oceanographic vessel and studied the variation rule of shipping noise under manoeuvring conditions, such as steering. Gaggero et al. [47] developed a post-processing software tool capable of processing the output data of the vertical array, which provided some information such as vertical directivity and horizontal directivity of the underwater radiated noise from transiting ships. Grelowska et al. [48] carried out experimental research on the underwater noise radiated from a small ship using classical propulsion and identified the main sources. In 2016, Simard et al. [28] carried out shipping noise measurement in the St. Lawrence channel, to a depth of $350 \mathrm{~m}$, and obtained the source spectrum levels of 255 merchant ships. The predicted source spectral levels were sensitive to the transmission loss models. In 2018, Zilong Peng et al. [49] made extensive measurements on the URN of a small fishing boat in the South China Sea, to $87 \mathrm{~m}$ depth, and proposed a predictive model to be applied to a typical fishing boat.

In recent years, with the support of the European Union, several large cooperative research teams (SILENV (Ship Innovative soLutions to rEduce Noise and Vibrations) project [50], AQUO (Achieve QUieter Oceans) project [30,51-56], SONIC (Suppression Of underwater Noise Induced by Cavitation) project $[38,57]$, and the MEPF (Marine Environment Protection Fund) project [58]) have carried out a large number of studies on shipping noise in European waters [59]. The AQUO project [30] can be divided into three stages: URN modelling of noise sources; noise mapping of merchant ships in specific sea areas; assessment of the impact of shipping noise on marine mammals. This project produced a series of reports and papers, which are an important reference for the research of shipping noise.

On the basis of SL empirical models, Hamson [60], Etter [61], Anon [62], Courtois [63], Colin [64], Audoly [65], Aulanier [66], Jones [67], Folegot [68], Soares [69], Erbe [70], Sertlek [71], and Buszman [72,73], devoted studies to the noise field produced by merchant ships in specific sea areas. Ainslie [35] and Carey [9] introduced the noise mapping of merchants ships in Principles of Sonar Performance Modelling and Ocean Ambient Noise Measurement and Theory, respectively. Kozaczka and Grelowska [74, 75] carried out an assessment of a range of acoustic disturbances generated by a ship sailing in shallow seas and developed a new, complex system for improving the security of the maritime infrastructure by means of many methods of observation, including acoustical methods in water.
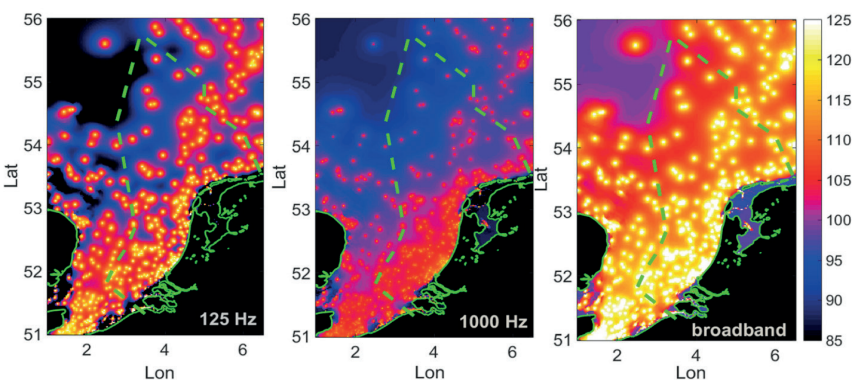

Fig. 4. Sound maps for the isovelocity case. Ship source depth is $5 \mathrm{~m}$. The wind generated sound is added to all maps [71]

\section{A SUMMARY OF EMPIRICAL SOURCE LEVEL MODELS}

Table 2 lists some of the SL empirical models. Their specific expressions, applicable conditions and the relations between these models are systematically sorted and summarised here. It should be noted that the 'three-parameter' model $[25,26]$ is not included here as it mainly deals with the adjustable pitch propeller used in a portion of current merchant ships. The basic relationships of the other SL models are shown in Fig. 5. In the dashed box, the AQUO project's model and the Wittekind's model are the representative SL models, based on a noise-generated mechanism. Among these models, the Wittekind's model was proposed earlier and it is the most complex model which takes some detailed ship parameters into consideration.

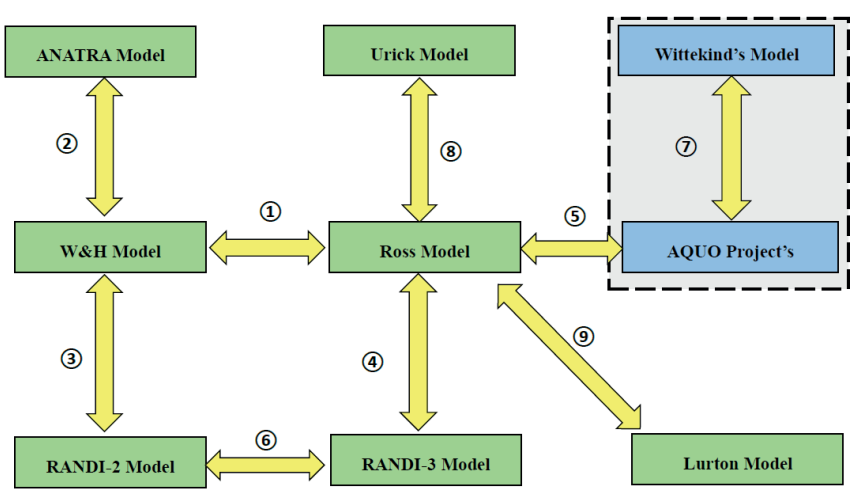

Fig. 5. Basic relationships of SL empirical models

\section{THE INTRODUCTION OF EMPIRICAL SOURCE LEVEL MODELS}

\section{(1) Ross model}

Ross [15] concluded several formulas for estimating the radiated noise of merchant ships in his classic publication 
Mechanics of Underwater Noise. He summarised the relationship between total sound pressure level (SPL) and the speed of ships within $8 \sim 24 \mathrm{kt}$ during World War II. At frequencies above $100 \mathrm{~Hz}$, the average curve fitting equations drawn (based on these data) are listed as follows,

$$
\begin{aligned}
& S L(f)=190+53 \lg \left(U_{a} / 10 k t\right)-20 \lg f, \\
& S L(f)=199+53 \lg \left(U_{a} / 15 k t\right)-20 \lg f
\end{aligned}
$$

where $U_{a}$ is the speed (kt) and $f$ is the frequency $(\mathrm{Hz})$. In the above formula, the average SL of different ships deviates from the average curve by about $\pm 4 \mathrm{~dB}$. Gaggero [76] called the first expression in Eq. (1) the Ross Speed model (R-S model).

In addition, Ross also derived several formulas for tonnage,

$$
\begin{aligned}
& S L(f)=132+50 \lg \left(U_{a} / 10 k t\right)+15 \lg D T-20 \lg f, \\
& S L(f)=154+60 \lg \left(U_{a} / 10 k t\right)+9 \lg D T-20 \lg f
\end{aligned}
$$

where $D T$ is vessel tonnage $(\mathrm{t})$. Both formulas gave similar results for ships during World War II. However, the displacements of modern supertankers have increased by more than 20 times and, for ships of this size, the SL difference predicted by these two formulas is as large as $10 \mathrm{~dB}$. As a result, these formulas are not suitable for vessels exceeding 30,000 tonnes. Gaggero [76] called the first expression in Eq. (2) the Ross Tonnage model (R-ST model). At the same time, these formulas only apply to spectral levels above $100 \mathrm{~Hz}$, the part below $100 \mathrm{~Hz}$ is generally considered to be flat.

In addition, Ross [15] believed that the cavitation noise power of the propeller is proportional to the total number of cavitation blades and propeller diameter. When studying shipping noise during World War II, for large ships, it was found that the average trend was significantly related to blade tip velocity $U_{t}$ and blade number $B$, but had nothing to do with other quantities. For ships with a length of more than $100 \mathrm{~m}$ (blade velocity range of $15 \sim 50 \mathrm{~m} / \mathrm{s}$ ), the SL can be expressed as follows:

$$
S L(f)=195+60 \lg \left(\frac{U_{t}}{25}\right)+10 \lg \left(\frac{B}{4}\right)-20 \lg (f)
$$

\section{(2) Urick model}

Urick [14] obtained the following fitting formula, according to 157 voyages of 77 ships of 11 different types, most being cargo ships, tankers and large warships:

$S L=51 \lg V+15 \lg T-20 \lg f_{k H z}+20 \lg D-13.5$

where $V$ is the velocity of propeller blade tip ( $\mathrm{ft} / \mathrm{s}), T$ is the displacement of the vessel (ton), $f_{k H z}$ is the frequency $(\mathrm{kHz})$, and $D$ is the distance (yards). It should be noted that the predicted results of the above formula have a standard deviation of $5.4 \mathrm{~dB}$ with individual measured values, which is only applicable when the propeller cavitation is the main noise source above $1 \mathrm{kHz}$.

When the speed of the propeller blade is unknown, a more convenient formula for calculating spectral level with ship speed can be used,

$$
R N L(f)=R N L_{1 K}-20 \lg \left(\frac{f}{1000}\right)
$$

where $K$ is the speed $(\mathrm{kt})$. This formula is consistent with the measurement level of passenger ships, transport ships and warships at $5 \mathrm{kHz}$, with a standard deviation of $5.5 \mathrm{~dB}$, but not applicable to cargo ships and tankers.

\section{(3) Lurton model}

In his book An introduction to underwater acoustics: principles and applications, Lurton [8] presented a simplified version of the Ross empirical model. There are two key parameters in the description of shipping noise level, i.e. the noise level at $1 \mathrm{kHz}\left(\mathrm{RNL}_{1 \mathrm{k}}\right)$ and the average or highest level of line spectrum at low frequencies below $100 \mathrm{~Hz}\left(\mathrm{RNL}_{\mathrm{SL}}\right)$. The low-frequency noise spectrum below $100 \mathrm{~Hz}$ is considered to be flat. The radiated noise levels above $100 \mathrm{~Hz}$ can be expressed as follows:

$$
R N L(f)=R N L_{1 K}-20 \lg \left(\frac{f}{1000}\right)
$$

\section{(4) W\&H model}

By measuring the shipping noise in the Mediterranean Sea and the Eastern Atlantic Ocean, Wales and Heitmeyer [16] gave the average SL in the frequency range of $30 \sim 1200 \mathrm{~Hz}$. The SLs in other frequency bands were obtained by interpolation, and the expression is:

$$
\bar{S}(f)=230-35.9 \lg f+9.17 \lg \left(1+\left(\frac{f}{340}\right)^{2}\right)
$$

\section{(5) ANRTRA model}

In 1980-1990, the French CERDSM research centre measured the noise data from 167 ships using sonobuoys. The SLs of all ships can be categorised into three levels: quiet, standard and noisy, i.e. the so-called ANATRA model [27]. The three types of source levels are defined as follows:

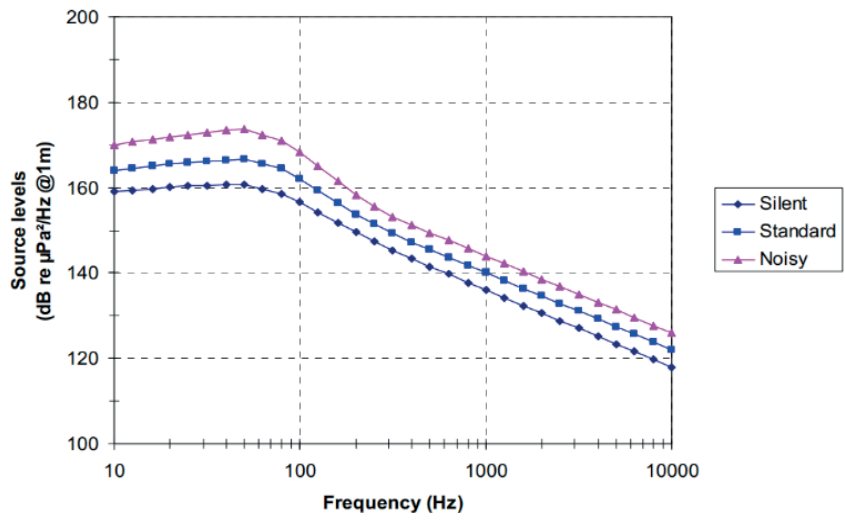

Fig. 6. URN patterns of merchant vessels for use in the ANATRA model [27] 


\section{(7) RANDI-2 model}

The RANDI-2 [17] model was developed by the U.S. Naval Research Laboratory on the basis of the W\&H model and Ross model. The specific expression is given as follows:

$$
S L=S v(f)+60 \lg \left(\frac{v}{12}\right)+20 \lg \left(\frac{L}{300}\right)
$$

where $S v(f)$ is given by the W\&H model. $L$ and $v$ are ship length (ft) and ship speed (kt), respectively.

\section{(8) RANDI-3 model}

On the basis of the RANDI-2 model, Breeding [17] made a further improvement. The ship length and the speed can be described by a uniform random distribution function and ships can be divided into five categories, according to length and speed: fishing boat, merchant ships, tankers, large tankers and super large tankers. The expressions are:

$L_{s}\left(f, v, l_{s}\right)=L_{s o}(f)+60 \lg \left(\frac{v}{12}\right)+20 \lg \left(\frac{L}{300}\right)+d f \times d l+3.0$

and

$d f=\left\{\begin{array}{cc}8.1, & 0 \leq f \leq 28.40 \\ 22.3-9.77 l g f, & 28.4 \leq f \leq 28.40, d l=l_{s}^{1.15} / 3643.0 \\ 0, & f>191.6\end{array}\right.$

The expression of the average SL is

$L_{\text {so }}(f)=\left\{\begin{array}{l}-10 \lg \left(10^{-1.06 \lg f-14.34}+10^{3.32 \lg f-21.425}\right), f<500 \mathrm{~Hz} \\ 173.2-18.0 \lg (f), f>500 \mathrm{~Hz}\end{array}\right.$

\section{(8) Wittekind's model}

Wittekind [23] was the first to attempt to model shipping noise according to noise-generating mechanisms. Shipping noise can be made up of low-frequency propeller cavitation noise, medium-high frequency propeller cavitation noise and medium-frequency diesel engine noise. By establishing a connection between some primary parameters influencing the shipping noise (displacement, critical speed of cavitation, block coefficients, mass of main engine and whether the main engine is installed elastically) and three major underwater radiation noise sources, the total source level is given by

$$
S L=10 \lg \left(10^{\frac{F_{1}}{10}}+10^{\frac{F_{2}}{10}}+10^{\frac{F_{3}}{10}}\right)
$$

where $F_{1}, F_{2}$ and $F_{3}$ are the low-frequency cavitation noise, medium-high frequency cavitation noise and diesel engine noise, respectively.

According to the work by Arveson and Vendittis, Wittekind [23] believed that the low-frequency noise component should be a function of speed, square coefficient and ship dimension,

$$
\begin{gathered}
F_{1}=2.2 \times 10^{-10} f^{5}-2 \times 10^{-7} f^{4}+6 \times 10^{-5} f^{3}-8 \times 10^{-3} f^{2}+0.35 f+125+A+B \\
A=80 \lg \left(\left(v / v_{C I S}\right) \cdot 4 \cdot c_{B}\right), B=10 \lg \left(\Delta / \Delta_{r e f}\right)^{2 / 3}
\end{gathered}
$$

where $A$ is the coefficient factor about the shipping speed and the square coefficient. $B$ and $c_{B}$ are the displacement factor and the square coefficient, respectively. $v$ and $v_{\mathrm{CIS}}$ are the speed (kt) and the cavitation critical speed (kt), respectively. $\Delta$ and $\Delta_{\text {ref }}$ are displacement and reference displacement, respectively.

The medium-high frequency propeller noise can be expressed as follows:

$F_{2}=-5 \ln (f)-\frac{1000}{f}+10+B+C, \quad C=60 \lg \left(\frac{1000 c_{B} v}{v_{C I S}}\right)$

where $C$ is another coefficient factor about the shipping speed and the square coefficient.

The medium-frequency diesel engine noise can be expressed as follows:

$F_{3}=10^{-7} f^{2}-0.01 f+140+D+E, D=15 \lg (m)+10 \lg (n)$

where $D$ is the simulation factor about the mass and the number of main engines. $E=0$ means elastic installation for the main engines and $E=15$ means rigid installation for the main engines. $m$ and $n$ are the mass $(t)$ and the number of main engines.

\section{(9) AQUO project's model}

The AQUO project's model [24] fully draws lessons from the Wittekind's model and Ross model but is different, in that the AQUO project's model takes into account the propeller non-cavitation noise. Audoly et al. believed that the shipping noise source mainly includes the mechanical noise, propeller non-cavitation noise and cavitation propeller noise. The total source level can be expressed as follows:

$$
\begin{aligned}
S L_{t}(f, V, L)= & 10 \lg \left(10^{S L_{\text {mach }}\left(f, V, L_{\text {ref }}\right) / 10}+10^{S L_{\text {prop }}\left(f, V, L_{r e f}\right) / 10}+\right. \\
& \left.+10^{S L_{\text {cav }}\left(f, V, L_{r e f}\right) / 10}\right)+25 \lg \left(L / L_{\text {ref }}\right)
\end{aligned}
$$

where each term can be expressed in terms of speed $V$ (kt) and frequency $f(\mathrm{~Hz}) . L$ is the ship length $(\mathrm{m})$ and $L_{\text {ref }}$ is the referenced ship length (m). Finally, 17 unknowns are determined by matching the measured data with the prediction formula.

\section{THE RELATIONSHIPS AMONG THESE EMPIRICAL SL MODELS}

(1) Relationship (1) between the Ross model and W\&H model

The W\&H model gives the average SL and its variation rule is only related to frequency $f$, while the Ross model gives an expression about ship speed, tonnage and frequency. Assuming that the average speed and the average tonnage are known, the Ross model can be degenerated into an average SL. Different from the Ross model, the effective frequency range of the $\mathrm{W} \& \mathrm{H}$ model is $30 \sim 1200 \mathrm{~Hz}$ and the SL at other frequencies are obtained by linear interpolation.

\section{(2) Relationship (2) between the W\&H model and ANATRA model}

The ANATRA model gives three different definitions of the SL of merchant ships: quiet, standard and noisy. However, 
unlike the W\&H model, the ANATRA model lacks a specific expression, only presenting several average SL curves.

\section{(3) Relationship (3) between the W\&H model and RANDI-2 model}

The RANDI-2 model completely adopts the average SL spectrum of the W\&H model as $S v(f)$. Therefore, the W\&H model is a degenerated form of the RANDI-2 model and the RANDI-2 model also absorbs the rules of the Ross model on ship speed and ship length.

\section{(4) Relationship (4) between the Ross model and RANDI-3 model}

Here we adopt the Ross tonnage model (R-ST model) in the second expression of Eq. (2). There is a certain relationship between ship length and tonnage, $D T=10^{-2.1} \mathrm{~L} 2.96$. Thus the Ross formula can be completely transformed into an expression about the ship length $L(\mathrm{~m})$,

$S L=154+60 \lg (v / 10)+9 \lg (D T)-20 \lg f=75.1+60 \lg v+27 \lg L-20 \lg f$

For the RANDI-3 model, the frequency band above $500 \mathrm{~Hz}$ is first investigated with the expression:

$$
S L=72.2+60 \lg v+20 \lg L-18 \lg f
$$

It should be noted that the ship length $L$ is converted into metres.

By comparing Eq. (17) with Eq. (18), it can be found that the Ross model and RANDI-3 model can be converted to completely similar forms for the frequencies higher than $500 \mathrm{~Hz}$, but the coefficients will be different. The SL predictions of the merchant ship with an assumed length of $100 \mathrm{~m}$, at $1 \mathrm{kHz}$, will have a discrepancy of $10.9 \mathrm{~dB}$ using the two models.

Secondly, for the frequencies of $100 \sim 500 \mathrm{~Hz}$, the RANDI-3 model has a relatively complex expression and only $L_{S O}$ is considered here:

$$
\begin{gathered}
L_{S O}(f)=-10 \lg \left(10^{-1.06 \lg f-14.34}+10^{3.32 \lg f-21.425}\right) \\
=-10 \lg \left[10^{3.32 \lg f-21.425}\left(10^{-4.38 \lg f+7.08}+1\right)\right] \approx-33.2 \lg f+214.3
\end{gathered}
$$

Although the initial form is non-linear, with respect to the logarithmic frequency, it can still be converted to a linear expression, which will be consistent with the Ross model. This is because the RANDI-3 model takes the hump characteristic below $100 \mathrm{~Hz}$ into account, rather than being flat as the Ross model suggests. However, it is also found that the RANDI-3 model has two different slopes in the two frequency bands above $500 \mathrm{~Hz}$ and $100 \sim 500 \mathrm{~Hz}$, and the latter has a steeper slope.

\section{(5) Relationship (5) between the AQUO project's model and Ross model}

The AQUO project's model is based on noise mechanisms and each term is a function of speed and frequency. Although these relationships cannot be directly obtained from the Ross model, they still draw lessons from Ross's early works. In addition, the relationship of SL with respect to ship length or tonnage adopts the Ross model, as indicated in Eq. (17).

\section{(6) Relationship (6) between the RANDI-2 model and RANDI-3 model}

By comparing Eq. (8) and Eq. (9), it is obvious that the forms of both models are very close. Furthermore, the RANDI-2 model employs the average SL spectrum of the W\&H model completely. In contrast, the RANDI-3 model defines the average SL spectrum segmented in frequency bands and the low-frequency part in the model can also reflect the typical 'hump' characteristics.

\section{(7) Relationship (7) between the AQUO project's model and Wittekind's model}

Both the AQUO project's model and the Wittekind's model are based on noise-generated mechanisms. The difference between them is that the former requires the measured noise data of a specific ship to obtain the coefficients of noise sources through optimisation. The Wittekind's model is a series of empirical formulas, which have not been fully verified.

(8) Relationship (8) between the Urick model and Ross model

By comparing Eq. (2) with Eq. (4), it is obvious that the coefficients about tonnage and frequency obtained by both models are exactly the same, but the Urick model employs the blade tip velocity of the propeller. Since the propeller tip velocity and the shipping speed are connected through an advanced ratio, it can be generally considered that the coefficients of both models about shipping speed are basically the same.

\section{(9) Relationship (9) between the Ross model and Lurton model}

The Lurton model was developed on the basis of the Ross model. The model takes two key parameters into account, namely the noise level at $1 \mathrm{kHz}\left(\mathrm{RNL}_{1 \mathrm{k}}\right)$ and the average or maximum level of line spectrum below $100 \mathrm{~Hz}\left(\mathrm{RNL}_{\mathrm{SL}}\right)$. Accordingly, the dependency of noise levels for a frequency above $100 \mathrm{~Hz}$ is completely consistent with the Ross model, as shown in Eq. (6).

\section{STANDARDS AND METHODS FOR MEASUREMENT OF SHIPPING NOISE}

The ANSI/ASA S12-64 (2009) measurement standard developed by the Acoustical Society of America (ASA) is the most widely used [31]. The standard is categorised into A, $\mathrm{B}$ and $\mathrm{C}$ grades to satisfy different accuracy requirements. In Grade C, a measurement method using s single hydrophone is recommended for investigation. A three-element array, with depression angles of $15^{\circ}, 30^{\circ}$ and $45^{\circ}$ are recommended for Grade A (accurate method) and Grade B (engineering method), and the closest distance shall not be less than $100 \mathrm{~m}$ or 1 times the ship length. Finally, the SL of a measured ship is 
the average SLs obtained from the three elements in the array. Figure 7 shows the measurement methodology specified in the ANSI/ASA S12-64 (2009) standard. The standard requires replicated, far-field, broadside measurements along three aspect angles, centred on a fixed closest point of approach (CPA). The measurements should be performed in a deep basin, 1 to 3 times the ship length (depending on the target grade level of the SL estimate), allowing free-field propagation between the source and receiver, with no interference from other sources and reverberation. The propagation loss from CPA to $1 \mathrm{~m}$ is estimated with spherical spreading. The SSLs averaged over the three measurement angles should be reported by integrating the energy per one-third octave bands, which facilitates inter-ship comparisons by smoothing the SSL narrowband variability. Other acoustic metrics commonly used for ship SLs are broadband levels integrated over a large bandwidth (e.g. $20 \mathrm{~Hz}$ to $1 \mathrm{kHz}$, or per octave bands) and narrow band SSL (for spectral levels in $1 \mathrm{~Hz}$ bands) $[28,41]$.
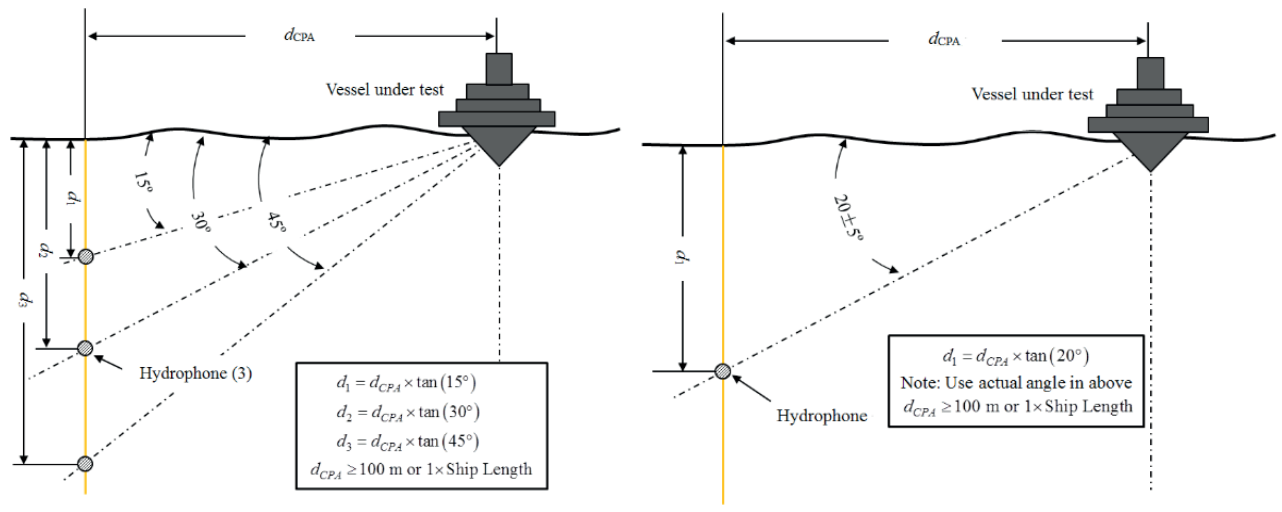

Fig. 7. measurement methodology presented in ANSI/ASA S12-64 (2009) (a) Grade A and B (b) Grade C [31]

Figure 8 shows the trajectory of the target vessel and the position of the hydrophone specified in the ANSI/ASA S12-64 (2009) standard. The target vessel travels at a constant speed along a straight line, turns away from two times the Data Window Length (DWL), and then continues the next round trip. The time window is taken to be $\pm 30^{\circ}$ near the closest point.

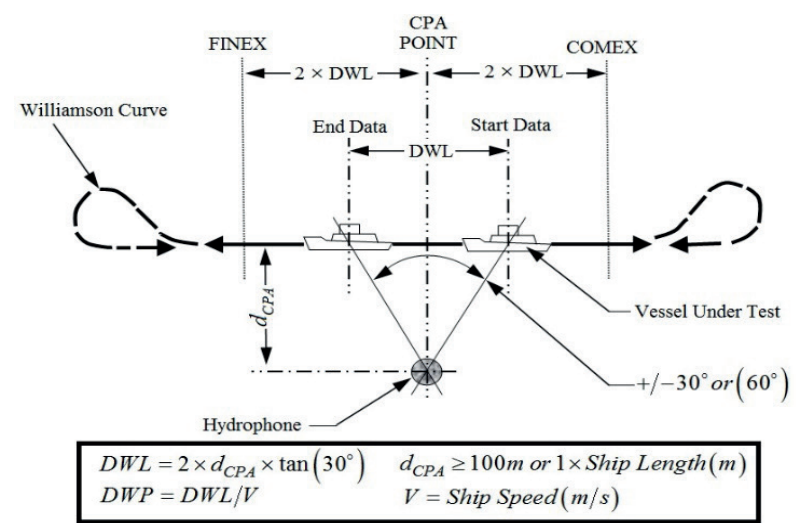

Fig. 8. The shipping trajectory of target vessel and position of hydrophone defined in ANSI/ASA S12-64(2009) [31]

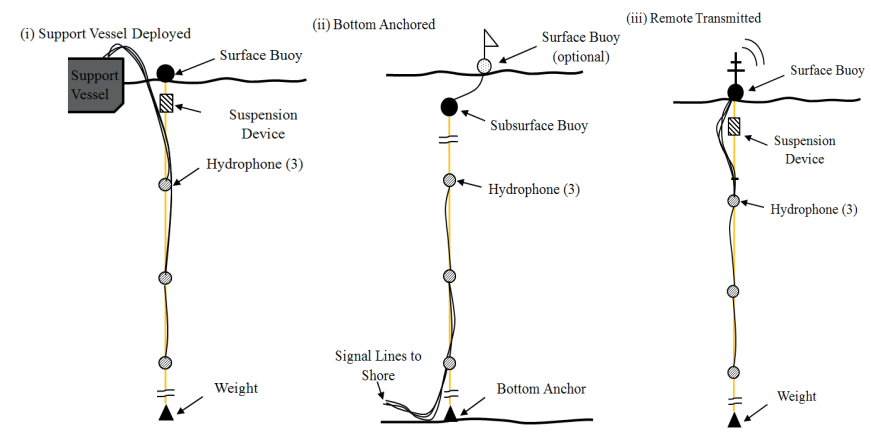

Fig. 9. Hydrophone deployment arrangements [31]

As shown in Fig. 9, the hydrophones are generally arranged in the above three ways. In September 2013, with the support of the SONIC project, Brooker and Humphrey [38] conducted underwater radiated noise measurements of the target ship Princess Royal, using the first method. A slight difference was that, in order to prevent the buoy and the measuring system from being carried away by the current, and also to isolate the vibration of the mother vessel to the measuring system, the buoy was connected with elastic ropes. The second measurement method is often applicable to the long-time noise monitoring for the observatory stations near the coast. Andrew et al. [5] used a method similar to the second method to observe ship noise on the west coast of North America for 13 years (1994-2007), but the hydrophone array was horizontally arranged on the seabed. The third measurement method, suitable for the simultaneous observation of a wide range of multiple measurement points, has been adopted by the CERDSM research centre in France [27]. In 1980-1990, they used the sonobuoy system to measure the noise of 167 ships and obtained the ANATRA model.

The DNV measurement standard [32] is mainly used for the classification and evaluation of the underwater radiation noise level of various ships; a single hydrophone is arranged on the seabed with a closest distance of 150 250 m, as shown in Fig. 10. The measurement can also be carried out in relatively shallow waters but the standard requires that the water depth below the keel should be more than $30 \mathrm{~m}$. 


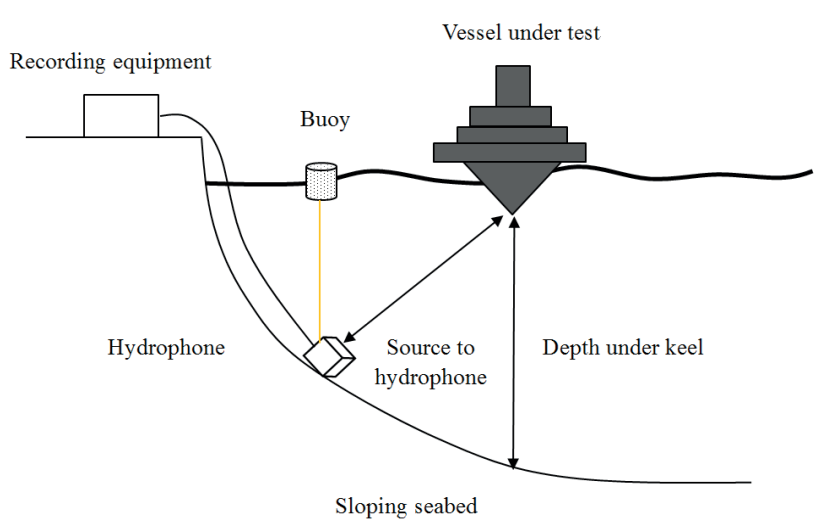

Fig. 10 Hydrophone deployment arrangements defined in DNV document

\section{CONCLUSIONS}

The aim of the present work has been to outline the empirical models and measurement techniques developed over recent years for studying shipping noise. These applications and research into shipping noise (both in the ocean and river channels) is still in an ongoing developmental phase and there are limitations and shortcomings that need to be overcome; further applications need to be explored. Presented in this section is a brief discussion regarding present limitations and the requirement for future developments.

\section{MORE ACCURATE EMPIRICAL SL MODELS}

The current empirical SL models listed in this paper were all developed based on numerous measurements. For the ship traffic noise mapping, the SL models of merchant ships are all treated as a monopole source, or equivalent monopole source considering radiation direction. However, this cannot reflect the real noise radiation patterns at different frequencies, especially at higher frequencies. Thus, a more accurate empirical SL model, regarding the noise generated from a whole merchant ship as being a combination of spatially separated monopole sources, dipole sources and multipole sources, is necessary to study and develop it further; this may generate more accurate, radiated noise field propagation in the ocean channels.

\section{THE CONNECTIONS BETWEEN EMPIRICAL MODELS AND NOISE SOURCE GENERATION MECHANISMS}

The current empirical models were always produced from measurements and statistics, and the coefficients used to fit the formulas lack practical physical meaning. For example, what does the dependence of source level on shipping speed or ship length represent? How can we create the connections between empirical models and noise source generation mechanisms? The present limitations require development for the future.

\section{ACKNOWLEDGEMENTS}

This work was supported by the Foundation Strengthening Program Area Fund of Science and Technology Commission of the Central Military Commission (No. 2020-JCJQ-JJ-228), Natural Science Foundation of Jiangsu Province (BK20200995), Scientific Research Start-Up Fund for Young Teachers of Jiangsu University of Science and Technology (1142931805) and the Institute of Acoustics of the Chinese Academy of Sciences (IOA, CAS). The authors would like to thank Professor Jun Fan from Shanghai Jiao Tong University for their suggestions. Finally, we would like to thank the anonymous reviewers for their insightful comments and helpful suggestions made.

\section{REFERENCES}

1. National Research Council: Ocean noise and marine mammals. National Academies Press (US), 2003.

2. Hermannsen, L., Beedholm, K., Tougaard, J., Madsen, P. T.: High frequency components of ship noise in shallow water with a discussion of implications for harbor porpoises (Phocoena phocoena), The Journal of the Acoustical Society of America, vol. 136(4), pp. 1640-1653, 2014.

3. McKenna, D.: Ship sources of ambient noise. IEEE Journal of Oceanic Engineering, 30(2), 257-261, 2005.

4. Chapman, N. R., Price, A.: Low frequency deep ocean ambient noise trend in the Northeast Pacific Ocean. The Journal of the Acoustical Society of America, 129(5), EL161-EL165, 2011.

5. Andrew, R. K., Howe, B. M., Mercer, J. A.: Long-time trends in ship traffic noise for four sites off the North American West Coast. The Journal of the Acoustical Society of America, 129(2), 642-651, 2011.

6. Zhu Beili, Huang Xiuchang.: Key Technologies for Submarine: Stealth Design of Acoustic Coating, Shanghai Jiao Tong University Press: Shanghai, China, 2012. (In Chinese)

7. Wenz, G. M.: Acoustic ambient noise in the ocean: Spectra and sources. The Journal of the Acoustical Society of America, 34(12), 1936-1956, 1962.

8. Lurton. X.: An Introduction to Underwater Acoustics. Berlin, Germany: Springer-Praxis, 2010.

9. Carey, W. M., Evans, R. B.: Ocean ambient noise: measurement and theory. Springer Science \& Business Media, 2011. 
10. Harrison, C. H.: Formulas for ambient noise level and coherence. The Journal of the Acoustical Society of America, 99(4), 2055-2066, 1996.

11. Harrison, C. H.: CANARY: A simple model of ambient noise and coherence. Applied Acoustics, 51(3), 289-315, 1997.

12. Zilong Peng, Bin Wang, Jun Fan.: Assessment on source levels of merchant ships observed in the East China Sea. Ocean Engineering, 156: 179-190, 2018.

13. Zilong Peng.: Measurement and modelling on the underwater noise radiated from ships in the area of Zhoushan Archipelago. Ph.D. Dissertation of Shanghai Jiao Tong University, 2018.

14. Urick, R. J.: Principles of Underwater Sound. McGraw-Hill Co, New York, 1983.

15. Ross, D.: Mechanics of Underwater Noise. Pergamon, New York, 1976.

16. Wales, S. C., Heitmeyer, R. M.: An ensemble source spectra model for merchant ship-radiated noise. The Journal of the Acoustical Society of America, 111(3), 1211-1231, 2002.

17. Breeding Jr, J. E., Pflug, L. A., Bradley, M., Walrod, M. H.: Research Ambient Noise DIrectionality (RANDI) 3.1 Physics Description (No. NRL/FR/7176--95-9628). Naval Research Lab Stennis Space Center MS, 1996.

18. Arveson, P. T., Vendittis, D. J.: Radiated noise characteristics of a modern cargo ship. The Journal of the Acoustical Society of America, 107(1), 118-129, 2000.

19. Veirs S, Veirs V, Wood J. D.: Ship noise extends to frequencies used for echolocation by endangered killer whales. PeerJ, 4: e1657, 2016.

20. Knudsen, V. O., Alford, R. S., Emling, J. W.: Underwater ambient noise. J. Mar. Res., 7, 410-429, 1948.

21. Piggott, C. L.: Ambient sea noise at low frequencies in shallow water of the Scotian Shelf. The Journal of the Acoustical Society of America, 36(11), 2152-2163, 1964.

22. Hamson, R. M., Wagstaff, R. A.: An ambient-noise model that includes coherent hydrophone summation for sonar system performance in shallow water (No. SACLANTCEN-SR-70). SACLANT ASW RESEARCH CENTRE LA SPEZIA (ITALY), 1983.

23. Wittekind, D. K.: A simple model for the underwater noise source level of ships. Journal of Ship production and design, 30(1), 7-14, 2014.
24. Audoly, C., Rizzuto, E.: AQUO: Achieve QUieter Oceans by shipping noise footprint reduction FP7-Collaborative project no314227, WP 2: Noise Sources, Task T2.1, "Ship underwater radiated noise patterns”, URL: www. aquo. eu., 2018.

25. Traverso, F., Gaggero, T., Rizzuto, E., Trucco, A.: Spectral analysis of the underwater acoustic noise radiated by ships with controllable pitch propellers. In OCEANS 2015-Genova (pp. 1-6). IEEE, 2015.

26. Traverso, F., Gaggero, T., Tani, G., Rizzuto, E., Trucco, A., Viviani, M.: Parametric analysis of ship noise spectra. IEEE Journal of Oceanic Engineering, 42(2), 424-438, 2016.

27. Esperandieu, J. S.: Prediction of horizontal ambient shipping noise directionality with an analytical model: ANATRA, 1990.

28. Simard, Y., Roy, N., Gervaise, C., Giard, S.: Analysis and modelling of 255 source levels of merchant ships from an acoustic observatory along St. Lawrence Seaway. The Journal of the Acoustical Society of America, 140(3), 2002-2018, 2016.

29. Gaggero, T., Rizzuto, E., Traverso, F., Trucco, A.: Comparing ship underwater noise measured at sea with predictions by empirical models. In proc. of 21st International Congress on Sound and Vibration: 1510-1516, 2014.

30. Audoly, C., Gaggero, T., Baudin, E., Folegot, T., Rizzuto, E., Mullor, R. S., ... Kellett, P.: Mitigation of underwater radiated noise related to shipping and its impact on marine life: A practical approach developed in the scope of AQUO project. IEEE Journal of Oceanic Engineering, 42(2), 373387, 2017.

31. ANSI/ASA.: Quantities and Procedures for Description and Measurement of Underwater Sound from Ships-Part 1: General Requirements, 2009.

32. Veritas, D. N.: Rules for classification of ships - part 6 chapter 24: Silent Class Notation, 2010.

33. Mitson, R. B.: Underwater noise of research vessels: review and recommendations. ICES Cooperative Research Report No.209. ISSN 1017-6195, 1995.

34. ISO 17208-1.: Underwater acoustics -- Quantities and procedures for description and measurement of underwater sound from ships -- Part 1: Requirements for precision measurements in deep water used for comparison purposes, 2016.

35. Ainslie, M. A.: Principles of sonar performance modelling. Berlin: Springer, 2010. 
36. De Jong, C. A. F.: Characterization of ships as sources of underwater noise. In NAG/DAGA International Conference on Acoustics, Rotterdamn, The Netherlands, 2009.

37. Coward, S.: A method for remote sensing of acoustic ship noise. Master's thesis, 2013.

38. Brooker, A., Humphrey, V.: Measurement of radiated underwater noise from a small research vessel in shallow water. Ocean Engineering, 120, 182-189, 2016.

39. Scrimger, P., Heitmeyer, R. M.: Acoustic source-level measurements for a variety of merchant ships. The Journal of the Acoustical Society of America, 89(2), 691-699, 1991.

40. Grelowska, G.: Study of Seasonal Acoustic Properties of Sea Water in Selected Waters of the Southern Baltic, Polish Maritime Research, 23(1), 25-30, 2016.

41. McKenna, M. F., Ross, D., Wiggins, S. M., Hildebrand, J. A.: Underwater radiated noise from modern commercial ships. The Journal of the Acoustical Society of America, 131(1), 92-103, 2012.

42. Coward, S., Tollefsen, D., Dong, H.: Radiated ship noise level estimates from measurements in a fjord. The Journal of the Acoustical Society of America, 134(5), 4150-4150, 2013.

43. Das, A.: Shallow ambient noise variability due to distant shipping noise and tide. Applied Acoustics, 72(9), 660-664, 2011.

44. Roth, E. H., Schmidt, V., Hildebrand, J. A., Wiggins, S. M.: Underwater radiated noise levels of a research icebreaker in the central Arctic Ocean. The Journal of the Acoustical Society of America, 133(4), 1971-1980, 2013.

45. Bassett, C., Polagye, B., Holt, M., Thomson, J.: A vessel noise budget for Admiralty Inlet, Puget Sound, Washington (USA). The Journal of the Acoustical Society of America, 132(6), 3706-3719, 2012.

46. Trevorrow, M. V., Vasiliev, B., Vagle, S.: Directionality and maneuvering effects on a surface ship underwater acoustic signature. The Journal of the Acoustical Society of America, 124(2), 767-778, 2008.

47. Gaggero, T., Bassetti, M., Firenze, E., Tesei, A., Trucco, A.: Processing strategies for evaluating the ship radiated noise using an underwater vertical array. In proc. of 2 nd Int. Conf. and Exhibition on Underwater Acoustics, 329-336, 2014.

48. Grelowska, G., Kozaczka, E., Kozaczka, S., Szymczak, W.: Underwater noise generated by a small ship in the shallow sea. Archives of Acoustics, 38(3): 351-356, 2013.
49. Zilong Peng, Jun Fan, Bin Wang.: Analysis and Modelling on Radiated Noise of a Typical Fishing Boat Measured in Shallow Water Inspired by AQUO Project's Model. Archives of Acoustics, 38(3): 351-356, 2018.

50. SILENV.: Ships oriented Innovative Solutions to Reduce Noise and Vibrations, FP7-EC Collaborative Research Project, 2009-2012.

51. Rizzuto, E., Audoly, C.: AQUO: Achieve QUieter Oceans by shipping noise footprint reduction FP7-Collaborative project n'314227, WP 2: Noise Sources, Task T2.2, "Predictive theoretical models for propeller”, URL: www. aquo. eu, 2015.

52. Hallander, J., Audoly, C.: AQUO: Achieve QUieter Oceans by shipping noise footprint reduction FP7-Collaborative project n³14227, WP 2: Noise Sources, Task T2.3, "Propeller noise experiments in model scale”, URL: www. aquo. eu, 2015.

53. Salinas, R., Audoly, C.: AQUO: Achieve QUieter Oceans by shipping noise footprint reduction FP7-Collaborative project no314227, WP 2: Noise Sources, Task T2.5, "Synthesis: Impact of propeller noise on global”, URL: www. aquo. eu, 2015.

54. Moreno, A., Audoly, C.: AQUO: Achieve QUieter Oceans by shipping noise footprint reduction FP7-Collaborative project n'314227, WP 2: Noise Sources, Task T3.1, "European URN Standard Measurement Method", URL: www. aquo. eu, 2015.

55. Salinas, R., Audoly, C.: AQUO: Achieve QUieter Oceans by shipping noise footprint reduction FP7-Collaborative project n'314227, WP 2: Noise Sources, Task T3.2, “On-site measurements-Experimental data for accurate identification and quantification of Cavitation Noise and other sources", URL: www. aquo. eu, 2015.

56. Andre, M., Audoly, C.: AQUO: Achieve QUieter Oceans by shipping noise footprint reduction FP7-Collaborative project no314227, WP 2: Noise Sources, Task T3.4, "In-situ measurements of ambient underwater noise along time in different areas with record of AIS data", URL: www. aquo. eu, 2015.

57. Brooker, A., Humphrey, V., Jansen, E.: Suppression of underwater Noise Induced by Cavitation, FP7-314394SONIC, Deliverable D2.5: Full Scale Radiated Noise Measurement, 2015.

58. Loughborough University Institutional Repository.: Measurement of underwater noise arising from marine aggregate dredging operations. Marine Aggregate Levy Sustainability Fund (MALSF), 2011.

59. Wright, E. B., Cybulski, J.: Low-frequency acoustic source levels of large merchant ships (No. NRL-8677). NAVAL RESEARCH LAB WASHINGTON DC, 1983. 
60. Hamson, R. M.: The modelling of ambient noise due to shipping and wind sources in complex environments. Applied Acoustics, 51(3), 251-287, 1997.

61. Etter, P. C.: Underwater Acoustics Modelling and Simulation: Principle, Techniques and application. Spon Press, New York, 2003.

62. Anon.: Ocean noise and marine mammals (National Research Council of the National Academies). The National Academies Press, Washington, D.C, 2003.

63. Hom, F. L. C., Kinda, F. G. B., Hom, S.: Statistical Ambient Noise Maps from Traffic at World and Basin Scales. Institute Of Acoustics, Cambridge, UK, 2016.

64. Colin, M. E., Ainslie, M. A., Binnerts, B., de Jong, C. A., Karasalo, I., Östberg, M., ... Clorennec, D.: Definition and results of test cases for shipping sound maps. IEEE, 2015.

65. Audoly, C., Flikeema, M.: Suppression of underwater Noise Induced by Cavitation, FP7-314394-SONIC, Deliverable D5.4: Guidelines for regulation on UW noise from commercial shipping, 2015.

66. Aulanier, F., Simard, Y., Roy, N., Bandet, M., Gervaise, C.: Groundtruthed probabilistic shipping noise modelling and mapping: Application to blue whale habitat in the Gulf of St. Lawrence. In Proceedings of Meetings on Acoustics 4ENAL (Vol. 27, No. 1, p. 070006). ASA, 2016.

67. Jones, E. L., Hastie, G. D., Smout, S., Onoufriou, J., Merchant, N. D., Brookes, K. L., Thompson, D.: Seals and shipping: quantifying population risk and individual exposure to vessel noise. Journal of applied ecology, 54(6), 1930-1940, 2017.

68. Folegot, T., Clorennec, D., Brunet, P., Six, L., Chavanne, R., van der Schaar, M., André, M.: Monitoring long term ocean noise in European waters. In OCEANS 2015-Genova:1-7, 2015.

69. Soares, C., Zabel, F., Jesus, S. M.: A shipping noise prediction tool. In OCEANS 2015-Genova:1-7, 2015.

70. Erbe, C., MacGillivray, A., Williams, R.: Mapping cumulative noise from shipping to inform marine spatial planning. The Journal of the Acoustical Society of America, 132(5), EL423-EL428, 2012

71. Sertlek, H. Ö., Binnerts, B., Ainslie, M. A.: The effect of sound speed profile on shallow water shipping sound maps. The Journal of the Acoustical Society of America, 140(1), EL84-EL88, 2016.

72. Buszman K., Gloza M.: Detection of Floating Objects Based on Hydroacoustic and Hydrodynamic Pressure
Measurements in the Coastal Zone, Polish Maritime Research, 27(2), 168-175, 2020.

73. Buszman K.: Analysing the Impact on Underwater Noise of Changes to the Parameters of a Ship's Machinery, Polish Maritime Research, 27(3), 176-181, 2020.

74. Kozaczka, E., Grelowska, G.: Propagation of Ship-Generated Noise in Shallow Sea, Polish Maritime Research, 25(2), 37-46, 2018.

75. Kozaczka, E., \& Grelowska, G.: Autonomous Platform to Protect Maritime Infrastructure Facilities, Polish Maritime Research, 26(4), 101-108, 2019.

76. Gaggero, T., Rizzuto, E., Traverso, F., Trucco, A.: Comparing ship underwater noise measured at sea with predictions by empirical models. In proc. of 21st International Congress on Sound and Vibration: 1510-1516, 2014. 


\title{
CONTACT WITH THE AUTHORS
}

\author{
Xiaowei Yan \\ e-mail:yanxwseri@163.com
}

Systems Engineering Research Institute,

16 Cuiwei Road, Haidian District, 100036 Beijing,

\section{China}

\section{Hao Song}

e-mail:songhaox@163.com

Systems Engineering Research Institute,

16 Cuiwei Road, Haidian District, 100036 Beijing,

\section{China}

\author{
Zilong Peng \\ e-mail:zlp_just@sina.com
}

Jiangsu University of Science and Technology, No.2 Mengxi Road, 212003 Zhenjiang,

China

\author{
Huimin Kong \\ e-mail:kongcnn@126.com
}

Jiangsu University of Science and Technology, No.2 Mengxi Road, 212003 Zhenjiang,

China

\section{Yipeng Cheng}

e-mail:346256152@qq.com

Jiangsu University of Science and Technology,

No.2 Mengxi Road, 212003 Zhenjiang,

\section{China}

\section{Linjiang Han}

e-mail:892328443@qq.com

Jiangsu University of Science and Technology, No.2 Mengxi Road, 212003 Zhenjiang,

\section{China}

